\title{
Where is my mind? A propósito da necessidade do teatro, dos Pixies, de Pasolini e da Polónia
}

\author{
Rui Pina Coelho
}

No mesmo momento em que em Portugal os cortes anunciados pelo governo no final de 2011 -

nomeadamente, a subida do IVA nos espectáculos de 6\% para $13 \%$ e um corte de $38 \%$ nos subsídios bianuais e plurianuais - e o cancelamento da abertura dos concursos públicos pontuais e anuais para 2012, noticiados em Abril, ameaçam de extinção a grande parte das estruturas em actividade e, aparentemente, nas salas de espectáculo tudo parece correr sem grandes sobressaltos, em Varsóvia, no final de cada espectáculo a que assistia, imediatamente após as palmas ou primeiros comentários de um público assaz crítico, subia sempre alguém ao palco para ler um manifesto. Nesse texto, os profissionais de teatro declaravam-se preocupados quanto ao futuro do teatro na Polónia. Dirigiam-se ao público, dizendo-se não afectos a nenhuma escola ou facção, alertando para a seriedade do momento e avisando que o que estava em causa era a própria sobrevivência do teatro na Polónia. Depois de explicarem o particular rosário de cortes e despedimentos que afectam as suas estruturas teatrais, os profissionais polacos declaravam:

\section{Admitimos que o teatro muda com o tempo, e que as estruturas institucionais devem mudar com ele - mas tal não deve acontecer à custa e em detrimento do teatro em si. Exigimos que os profissionais de teatro tenham algo a dizer em qualquer decisão relacionada com o futuro do teatro na Polónia, exigimos um debate sobre um sistema de financiamento, em que a rentabilidade não seja o único critério. 0 teatro não é uma empresa nem um objecto de consumo, e os espectadores não são clientes. Em vez de dizermos não aos artistas, digamos não aos políticos incompetentes. (Tradução minha, do inglês)}

Sei bem que este tipo de comparações, como a que estou a fazer entre a situação portuguesa e a polaca, sofrem sempre de uma grande dose de ignorância e de ingenuidade. Mas ao ouvir este manifesto não era no teatro polaco que pensava. Pensava no português. Onde está a minha cabeça, perguntava-me eu.

E foi essa a mesma pergunta que me assombrou durante vários dias, mais concretamente, de 26 a 30 de Março de 2012, ao longo do XVI Congresso da Associação Internacional de Críticos de Teatro (AICT-IATC). Celebrado no contexto do festival Warszawskie Spotkania Teatralne (uma organização do Instituto Teatral Zbigniew Raszewski), e tendo como anfitriã a seç̧ão polaca da AICT, presidida por Tomasz Milkowski, para além de se entregar o Prémio Thalia à indiana Kapila Vatsyayan, debateu-se ali "0 teatro para lá do teatro" (Theatre Beyond the Theatre/Le Théâtre hors du Théâtre), em torno de questões como a utilização de espaços alternativos na cena contemporânea, a concepção de novas dramaturgias, casos exemplares de cruzamento de linguagens e disciplinas, o teatro ao serviço de estratégias de trabalho comunitário ou de projectos políticos, e, mais precisamente, como se relaciona a crítica de teatro com todas estas questões; em suma, o teatro para lá do teatro. E a minha cabeça em Lisboa, a pensar num teatro ameaçado de morte, sem tempo nem espaço para reflectir. Where is my mind?, perguntava eu, como na canção dos Pixies.

Mas o teatro polaco - descrito pelo Presidente de AICT, o sul coreano Yun-Cheol Kim, como "profundo, lento, negro, intenso, cínico, filosófico" ${ }^{1}$ - devolvia-me todas estas questões com fúria solidária. Os espectáculos a que assisti confrontavam-se todos, de uma ou outra maneira, com a história nacional polaca ou com motivos históricos, desde o sempre presente trauma de Auschwitz até às polémicas mais recentes em torno da organização do Campeonato Europeu de Futebol (em conjunto com a Ucrânia), para o próximo Julho. Tudo servia para esquissar interessantes libelos de como o teatro pode e é capaz de interpelar o real com pertinência, inteligência e, em alguns casos até, perigo libertário.
Rui Pina Coelho

integra a direcção da Associação Portuguesa de Críticos de Teatro, é doutorando em Estudos de Teatro da Universidade de Lisboa, professor da Escola Superior de Teatro e Cinema e autor do livro Casa da Comédia: Um palco para uma ideia de teatro (1946-1975) publicado pela

Imprensa NacionalCasa da Moeda em 2007.

Em texto publicado no Livro de apresentação e resumos do Congresso, p. 11 
III Furies,

de Sylwia Chutnik,

Stefan Dambski

e Madga Fertacz,

enc. Marcin Liber,

Modjeska Theatre, 2012,

fot. Karol Budrewicz.

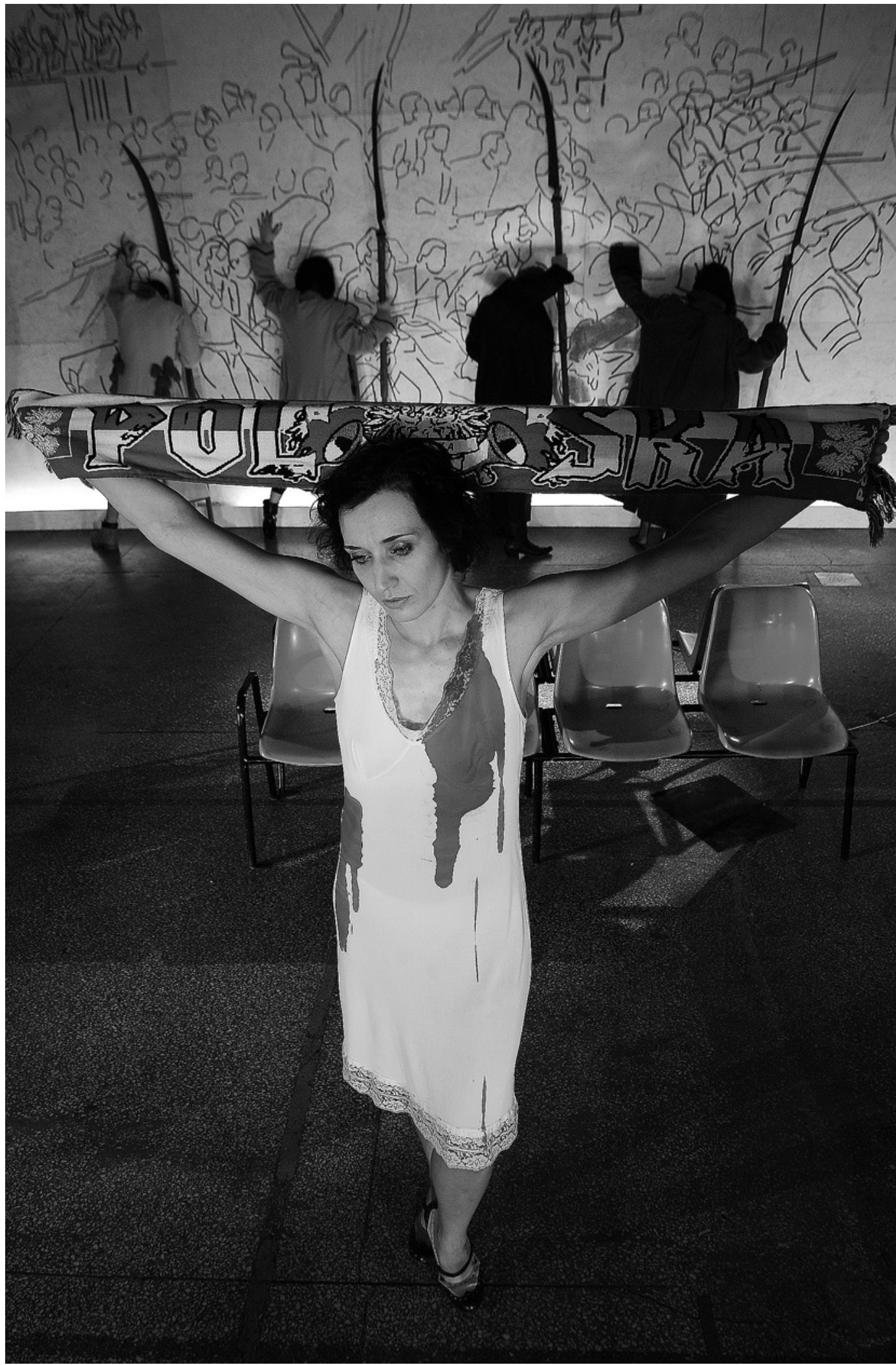

Se os espectáculos Work about Mother and Homeland T.E.O.R.E.M.A.Te Sierakowski trabalhavam com os voláteis contornos da alegoria, da moralidade ou da distopia respectivamente, III Furies e Rainbow Stand 2012

colocavam-se numa posição mais frontal em relação ao real, convocando a ocupação nazi - e o pós-guerra -, e o futuro Campeonato Europeu de Futebol.
Assim, Work about Mother and Homeland é essencialmente um trabalho de pesquisa sobre a identidade da Polónia. 0 prestigiado encenador Jan Klata compõe uma alegoria, traçada a espaços com toques de humor, caricatura, mas imbuida dum tom de solene misticismo, ensaiando uma revisão sobre o mito da maternidade, fazendo equivaler a história da Polónia e os seus momentos 


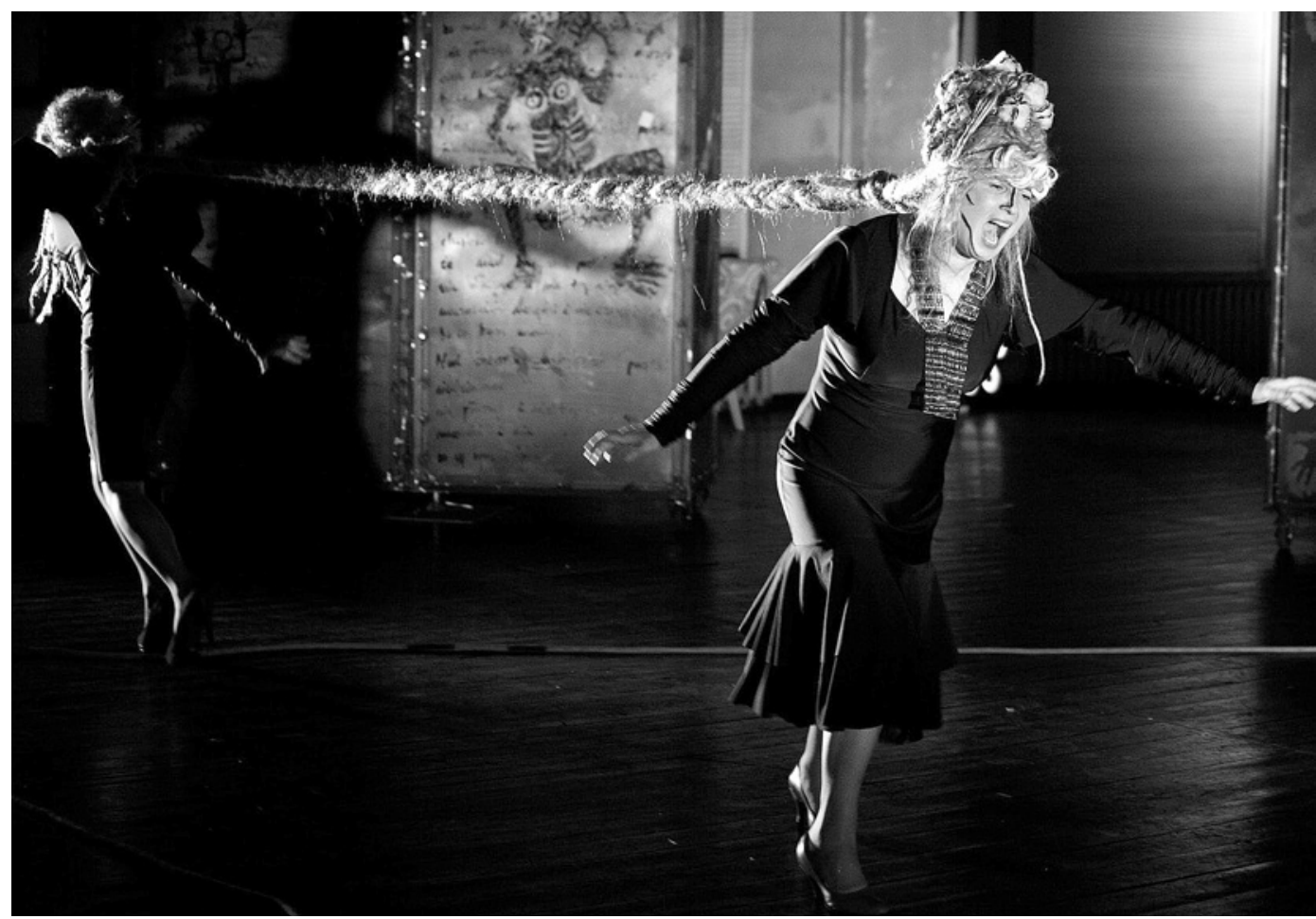

Work about Mother and Homeland, de Bozena Keff, enc. Jan Klata, Teatr Polsk in Wroclaw, 2012, fot. Natalia Kabanow. de subserviência e domínio a uma luta contra o domínio patriarcal. Assim, com canções, lamentos, danças, rituais, gritos, ladainhas ou diálogo, seis actores (cinco mulheres e um homem) com saltos altos, vestidos uniformemente de preto, usando várias máscaras, iam criando fugazes quadros onde o tema é desenvolvido. Orgulho pátrio (/mátrio) e História, tudo narrado à luz de relações homensmulheres ou mães-filhas. Com um dispositivo cénico simples (cinco armários que, uma vez abertos, serviam de moldura aos quadros narrativos, criando casas,

confessionários, jardins...), e uma ambiência de um carnaval triste, caricatural, grave, o espectáculo era dominado pela criação de uma paisagem sonora de grande efeito, onde as vozes das actrizes, os sons e a música se aliavam para criar uma atmosfera de grande envolvência sensorial.

Future Tales (Sierakowski) - o espectáculo do colectivo komuna // warszawa, que normalmente combina elementos de performance, dança e video art, sucedâneo do grupo anarquista Komuna Otwock - ficcionava a vida futura de Slawomir Sierakowski (n.1979), jovem líder de um grupo de intelectuais de esquerda - Krytyka Polityczna (Crítica Política) - que tem mudado "o vocabulário da política polaca, popularizando termos praticamente inexistentes desde a transformação de sistema em 1989: exclusão, desigualdade, participação, pós-política. Também trouxe a crítica ao capitalismo para o debate público", afirma-se no programa. 0 espectáculo elaborava sobre a hipótese "e se?", inventando várias futuras possiveis biografias para Sierakowski - do desencantado ao vitorioso, do vendido ao ermita, inventavam-se hipotéticas saídas para a situação presente - partindo sempre do princípio que o futuro permanece em aberto. Construído como uma colecção de quadros, todos subordinados a uma data e a um episódio da vida de Sierakowski, as referências iam-se cruzando, convocando-se alusões ou citações de Slavoj Zizek, Alain Badiou, Jacques Rancière, Chantal Mouffe, Peter Sloterdijk, Richard Rorty, entre outros. Dois músicos, um de cada lado da sala onde se apresentou o espectáculo, com violoncelo e guitarra eléctrica, iam construindo uma ambiência futurista ou de ficção científica, onde três actores iam criando pequenos quadros de beleza tosca e apressada, com objectos do quotidiano (espelhos, comida, roupa...) e jogando sobretudo fisicamente. Mas mais uma vez, a noção de identidade nacional se apresentava como a estrutura base do espectáculo, embora desta feita, à luz de uma forte pulsão derrisória e irónica (noutras gramáticas, pós-dramática).

T.E.O.R.E.M.A.T do multi-premiado Grzegorz Jarzyna - um dos mais relevantes criadores polacos da actualidade - é uma pequena pérola de inteligência e criatividade. Estreado em 2009, na Schaubühne am Lehniner Platz em Berlim, adapta o filme Teorema (1968) de Pier Paolo Pasolini, com autoridade, invenção e, muito, pensamento. No filme de Pasolini um misterioso jovem surge na vida de uma típica família burguesa, envolvendo-se sexualmente com todos os seus membros: da criada beata ao filho sensivel, da mãe sexualmente reprimida à tímida filha; até ao austero pai, o proprietário de uma fábrica. Com a súbita e misteriosa partida do jovem, caem todos em estados de estúpida privação e desespero: a mãe entrega-se à luxúria de jovens rapazes, o filho torna-se um artista frustrado, a filha mergulha num estado catatónico; a criada regressa ao campo; e o pai, o rico proprietário, decide libertar-se de todas as posses e entregar a sua fábrica aos trabalhadores.

No espectáculo, na primeira cena, sentado a uma mesa, Paolo, de frente para o público, responde a alegadas perguntas de jornalistas - confirma-se proprietário, capitalista, determinado e decidido. As sequências seguintes erguem o dia-a-dia da familia em quadros vivos de singeleza irrepreensivel: sem palavras, gestos demorados e longos, numa sala com três paredes, sinalizando uma requintada casa. De ambiente delicado, sons distantes e luz amena, constrói-se uma "tela" que será interrompida 


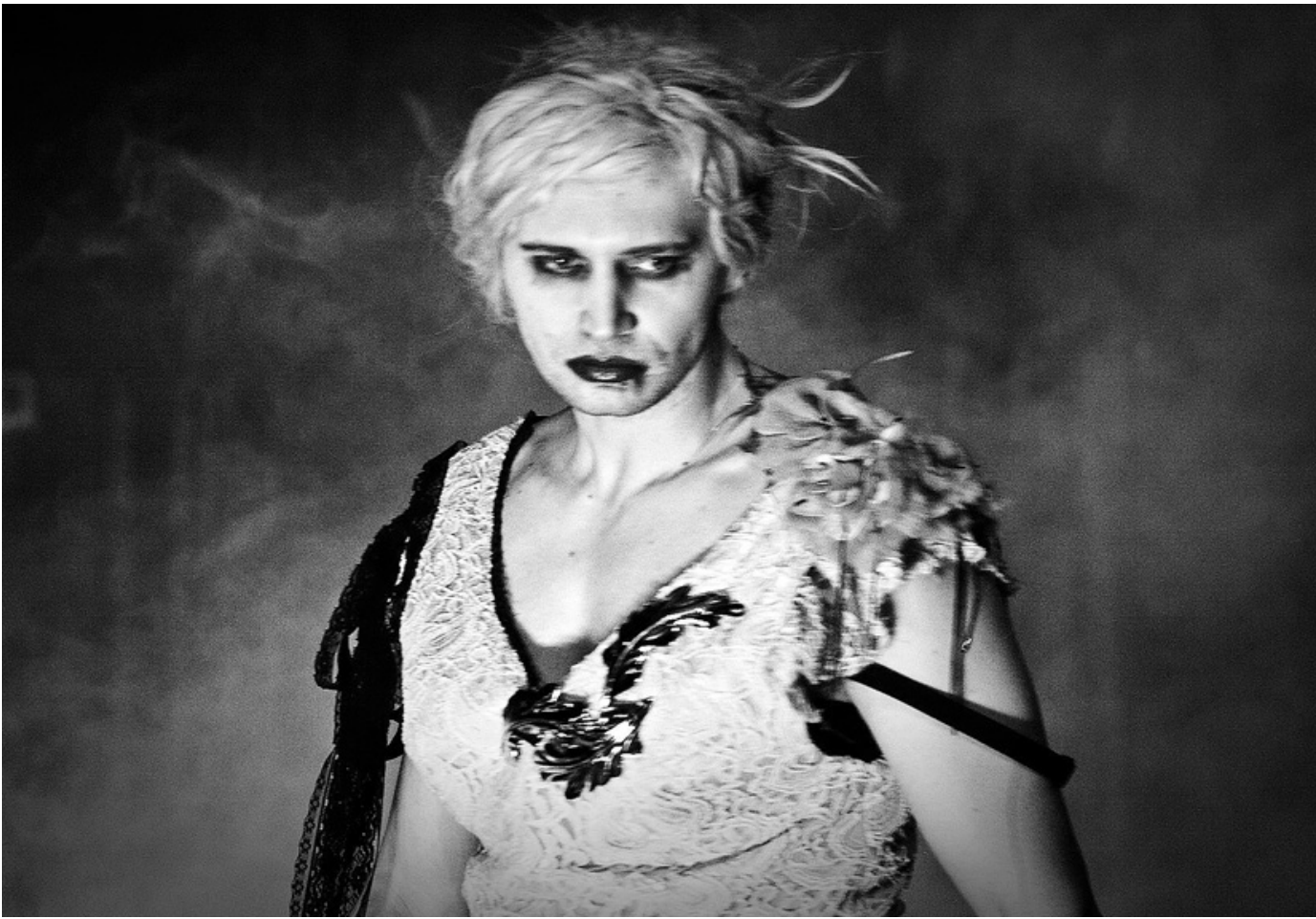

Rainbow Stand 2012, de Pawel Demirski, enc. Monika Strzepka, Teatr Polski Wroclaw,

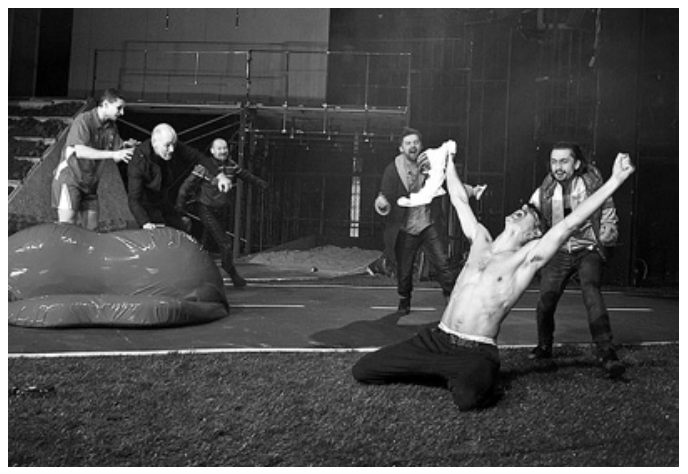

pela violência das relações. A ligar as cenas, um carteiro que anuncia a chegada e a partida do inesperado hóspede figura clownesca que salpica de cor a passiva ambiência de toda a existência burguesa.

Jarzyna guarda o radical do trabalho de Pasolini e fálo habitar numa cínica alegoria construida para os tempos modernos - uma sibilina moralidade sobre o capitalismo, o poder e a rápida erosão dos valores burgueses quando confrontados com a Paixão, que no léxico pasoliniano tanto pode assumir contornos bíblicos como de pura respiração carnal, levando as personagens da hipocrisia social à aguda percepção da volatilidade da vida.

Mas os espectáculos que mais violentamente me interrogavam sobre o paradeiro da minha cabeça seriam III Furiese Rainbow Stand 2012. A frontalidade das suas dramaturgias desarmavam quaisquer arcos metafóricos. 0 primeiro revisitava a ocupação alemã e o pós-Segunda Guerra Mundial com o comunismo, fazendo da plataforma de uma estação de comboios uma espécie de purgatório para exorcizar os lugares comuns da identidade polaca. 0 espectáculo, pautado sempre por uma música punkruidosa e exasperada, com uma banda ao vivo a um canto da sala -, misturando a narrativa de Baby de Sylwia Chutnik e os motivos de The Executor, de Stefan Dambski, convocava

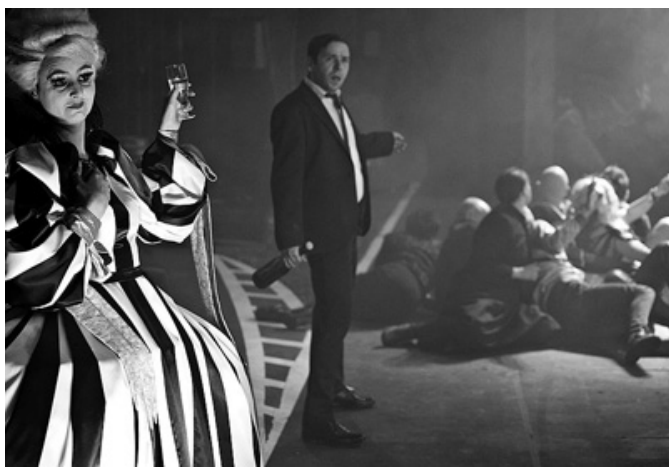

passado e presente, causas e consequências, colaboradores e vítimas, inocentes e culpados, ocupação fascista e passado comunista, problematizando as narrativas históricas mais estabilizadas e voltando a abrir feridas. 0 espectáculo, construido com limpeza, erguia figuras como uma prostituta, um sem-abrigo, um casal homossexual, uma mãe ou um padre que iam fazendo desfiar uma narrativa recortada a distorções punk. Numa das cenas mais icónicas do espectáculo, uma mulher em figura crística erguia um cachecol da selecção polaca de futebol: agónica, fazia convergir um passado de sacrificios individuais à disfórica exaltação nacionalista que o Campeonato Europeu de Futebol se prepara para explorar.

0 mesmo tópico foi o escolhido pela dupla Strzepka / Demirski que faz, em Rainbow Stand 2012, do Euro 2012 o locus para a exploração dos valores democráticos no capitalismo, da - mais uma vez - identidade nacional, da necessidade da modernização e do papel do activismo. A narrativa é simples: a comunidade gay de Varsóvia quer ver construída no Estádio Nacional uma "bancada arcoiris" para os adeptos homossexuais. Ainda que na primeira parte as figuras criadas pelos actores estejam

lamentavelmente perto de caricaturas, o espectáculo vai ganhando densidade, poder de reflexão e intencionalidade 


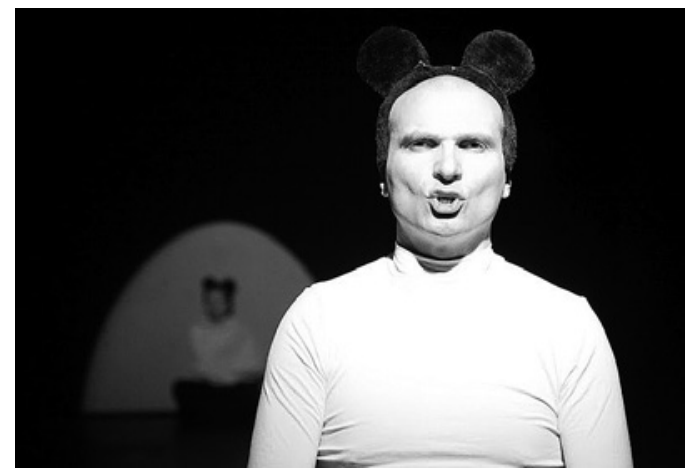

crítica à medida que avança. E isto acontece muito por culpa de uma banda sonora pautada a registo rock, interpretada ao vivo pelos actores (Nirvana, The Clash...) - mas sobretudo por uma canção que seria como que um refrão para todo o espectáculo: Where is my mind? dos Pixies.

0 palco aparece como se estivesse em construção: uma bancada coberta de terra, parte do chão coberto de relva, uma estrada que não leva a lado nenhum; ao cimo uma enorme tela onde se projectam pequenos vídeos e várias legendas comentando a acção - numa lateral, vidro transparente, deixando ver a bela plateia do Teatr Dramatyczny. Aí, desfiavam-se os tiques da corrupção no futebol, na política, na construção civil, mas,

essencialmente, revelava-se como um Estado ignorante, autista e alimentado a champanhe pode atropelar e esmagar as vidas dos seus cidadãos, reflectindo como o afastamento dos Estados das reais necessidades dos seus membros pode levar ao colapso - sistémico e, mais trágico, ao pessoal.

No final, já depois de uma pungente interpretação de Where is my mind? por parte de um dos actores, comigo ficava a mesma questão: onde está a minha cabeça? Estaria num teatro capaz de fazer estourar as narrativas oficiais? Num teatro capaz de discutir o passado e o futuro? De desarmar identidades nacionais? De criar assombrosas moralidades? Num teatro que não renuncia ao seu papel transformador? Mas entretanto, de Lisboa, chegavam notícias de um Estado que parece não encontrar qualquer necessidade para o teatro. Onde está a minha cabeça? pergunto eu.

\section{Notas sobre os espectáculos:}

Work about Mother and Homeland. Autor: Bozena Keff. Encenação: Jan Klata. Produção: Teatr Polski in Wroclaw. Local e data de apresentação no Warszawskie Spotkania Teatralne: Teatr Imka, 26 Março 2012.

T.E.O.R.E.M.A.T. Autor: Pier Paolo Pasolini. Encenação: Grzegorz Jarzyna. Produção: TR Warszawa. Local e data de apresentação: TR Warszawa, 27 Março 2012.

Sierakowski. Autoria colectiva: komuna//warszawa. Produção: komuna//warszawa. Local e data de apresentação: Lubelska 30/32 28 de Março de 2012.

III Furies. Autores: Sylwia Chutnik (Baby/Dzidzia) e Stefan Dambski (The Executor/Egzekutor) e Magda Fertacz. Encenação: Marcin Liber. Dramaturgia: Malgorzata Sikorska-Miszczuk. Produção: Modjeska Theatre. Local e data de apresentação no Warszawskie Spotkania Teatralne: Teatr Studio, 29 de Março 2012.

Rainbow Stand 2012. Autor: Pawel Demirski. Encenação: Monika Strzepka. Produção: Teatr Polski Wroclaw. Local e data de apresentação no Warszawskie Spotkania Teatralne: Teatr Dramatyczny, 30 de Março 2012. 